\title{
FAKTOR-FAKTOR YANG BERHUBUNGAN DENGAN KELUHAN CARPAL TUNNEL SYNDROME (CTS) PADA PETUGAS OPERATOR PENGISI BBM DI SPBU KOTA KENDARI
}

\author{
Pitrah Asfian ${ }^{1}$, Akifah ${ }^{2}$, Muh Jayandi ${ }^{3}$ \\ ${ }^{1}$ Bagian Kesehatan dan Keselamatan Kerja, Fakultas Kesehatan Masyarakat, Universitas Halu Oleo, \\ Kendari, Indonesia \\ ${ }^{2}$ Bagian Program Studi Kesehatan Masyarakat, Fakultas Kesehatan Masyarakat, Universitas Halu \\ Oleo, Kendari, Indonesia \\ ${ }^{3}$ Peminatan Kesehatan dan Keselamatan Kerja, Fakultas Kesehatan Masyarakat, Universitas Halu \\ Oleo, Kendari, Indonesia \\ ${ }^{*}$ Coressponding author: Muhiayandi@gmail.com
}

\section{ABSTRAK}

Carpal Tunnel Syndrome disebabkan oleh beberapa faktor yaitu faktor okupasi seperti getaran, lama kerja, gerakan repetitif, postur kerja, dan masa kerja dan faktor non okupasi seperti riwayat penyakit, riwayat merokok, status gizi, umur, status kehamilan dan jenis kelamin. Salah satu jenis pekerjaan yang mempunyai aktivitas gerakan berulang dalam jangka waktu yang lama adalah operator pengisi Bahan Bakar Minyak (BBM) di Stasiun Pengisian Bahan Bakar Minyak (SPBU) ketika menekan nozzle. Penelitian ini bertujuan untuk mengetahui faktor-faktor yang berhubungan dengan keluhan Carpal Tunnel Syndrome pada petugas operator pengisi BBM di SPBU Kota Kendari. Metode dalam penelitian ini adalah penelitian analitik cross sectional menggunakan uji Chi-square dan Fisher's exact. Variabel dalam penelitian ini adalah postur kerja, masa kerja, gerkan berulang, riwayat penyakit, dan status gizi dengan keluhan Carpal Tunnel Syndrome.Intrumen dalam penelitian ini adalah informed konsent, lembar hasil phalen test, lembar observasi rapid upper limb assesment, microtoise, boston carpal tunnel questionnaire, timbangan berat badan dan stopwatch. Sampel dalam penelitian ini sebanyak 64 orang dengan teknik pengambilan sampel proportionalrandom sampling. Hasil penelitian ini terdapat hubungan antara postur kerja $(\rho$-value $=0,000)$, masa kerja $(\rho$-value $=0,012)$, gerakan berulang $(\rho$-value $=0,019)$, namun tidak terdapat hubungan antara riwayat penyakit $(\rho$-value $=$ $0,188)$, status gizi ( $\rho$-value $=0,544)$. Dapat disimpulkan bahwa postur kerja, masa kerja, gerakan berulang berhubungan dengan Carpal Tunnel Syndrome.

Kata Kunci: Carpal Tunnel Syndrome, Gerakan berulang, Postur kerja

\section{PENDAHULUAN}

Menurut

International Labour

Organization (ILO), Muskoloskeletal Disorders (MSDs) adalah penyakit yang paling banyak terjadi di semua negera bagian Uni Eropa. Salah satu jenis musculoskeletal disorders adalah Carpal Tunnel Syndrome. Carpal Tunnel Syndrome (CTS) merupakan penyakit yang timbul akibatterhimpitnya saraf tepi di pergelangan tangan yang melewati terowongan karpal. ${ }^{1}$ Carpal Tunnel Syndrome disebabkan adanya pergerakan meluruskan dan membengkokkan sendi secara terus-menerus sehingganervus medianus dihimpit olehcarpal ligament dan menyebabkan munculnya rasa tidak nyaman pada tangan seperti kesemutan dan mati rasa. ${ }^{2}$

Prevalensi Carpal Tunnel Syndrome diperkirakan 1,55\% oleh National Health Interview Study (NHIS). Cummulative Trauma Disorders melebihi angka $50 \%$ dari semua penyakit akibat kerja di United States of America, diantaranya adalah Carpal Tunnel
Syndrome dimana setiap tahun kejadiannya sampai 267 dari 100.000 banyaknya populasi, dimana laki-laki tercatat $6 \%$ dan perempuan 9,2\%. Di Amerika kejadian Carpal Tunnel Syndrome tercatat 5\% namun Inggris melebihi angka tersebut mencapai $6 \%-17 \%$ kejadian. $^{3}$

Carpal Tunnel Syndrome disebabkan oleh beberapa faktor yaitu faktor okupasi seperti getaran, lama kerja, gerakan repetitif, postur kerja, dan masa kerja dan faktor non okupasi seperti riwayat penyakit, riwayat merokok, status gizi, umur, status kehamilan dan jenis kelamin. ${ }^{4}$

Hasil observasi dan wawancara terhadap 6 orang responden operator pengisi BBM di dua SPBU Kota Kendari didapatkan $50 \%$ yang merasakan keluhan gejala Carpal Tunnel Syndrome. Responden merasakan nyeri dan kesemutan pada pergelangan tangan ketika selesai beraktifitas, saat malam hari, dan setelah dilakukannya phalen test. Responden mengatakan telah bekerja $\geq 4$ Tahun sebagai operator pengisi BBM. Aktivitas kerja operator 


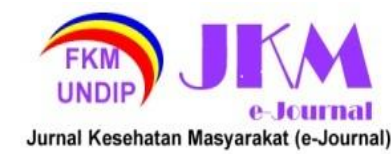

pengisi BBM di SPBU tidak lepas dari pergerakan manus, phalanges manus, dan carpaldalam menekan nozzle didapatkan $100 \%$ operator pengisi BBM melakukan gerakan berulang. Gambaran postur tubuh operator pengisi BBM ketika bekerja diukur menggunakan lembar penilaian Rapid Upper Limb Assesmentyaitu 66\% berisiko sedang dan $34 \%$ berisiko kecil sedangkan untuk status gizi pekerja dengan memperhitungkan indeks massa tubuh didapatkan $83 \%$ normal dan $17 \%$ kelebihan berat badan tingkat ringan.

Mengacu pada uraian di atas maka peneliti bermaksud untuk melakukan penelitian secara mendalam mengenai faktor-faktor yang memiliki hubungan dengan keluhan Carpal Tunnel Syndrome pada petugas operator pengisi BBM di SPBU Kota Kendari Tahun 2020.

\section{METODE PENELITIAN}

Penelitian ini menggunakan penelitian analitik melalui pendekatan cross sectional dimana pengamatan variabel dependen dan independen dipantau pada priode yang sama.

Penelitian ini memiliki populasi sebanyak 175 dengan jumlah sampel sebanyak 64 orang. Teknik sampling yang digunakan yaitu Proportionalrandom sampling dimana dalam menentukan sampel, peneliti menetapkan perwakilan dari setiap kelompok yang berada dalam populasi dimana jumlahnya disesuaikan dengan jumlah anggota yang ada pada setiap kelompok. Kemudian dilakukan pengamabilan sampel secara acak sederhana dengan mengundi nama-nama petugas operator pengisi BBM.

Instrumen pengambilan data menggunakan Lembar kuesioner BCTQ (Boston Carpal Tunnel Questionnaire), informed konsent, hasil phalen's test, observasi Rapid Upper Limb Assesment,microtoise, timbangan berat badan, dan Stopwatch. Variabel independen dalam penelitian ini adalah postur kerja, masa kerja, gerakan berulang, riwayat penyakit, status gizi. Variabel dependen dalam penelitian ini adalah Keluhan Carpal Tunnel Syndrome. Pengolahan data: editing, codding, entri, cleaning, dan tabulasi. Analisa data menggunakan analisis univariat dan bivariat. Analisis bivariat untuk menguji perbedaan atar variabel maka menggunakan uji Chi-square dan menggunakan $\alpha=0,05$.

HASIL

Karateristik responden dalam penelitian ini meliputi usia, jenis kelamin, status pernikahan, pendidikan terakhir:

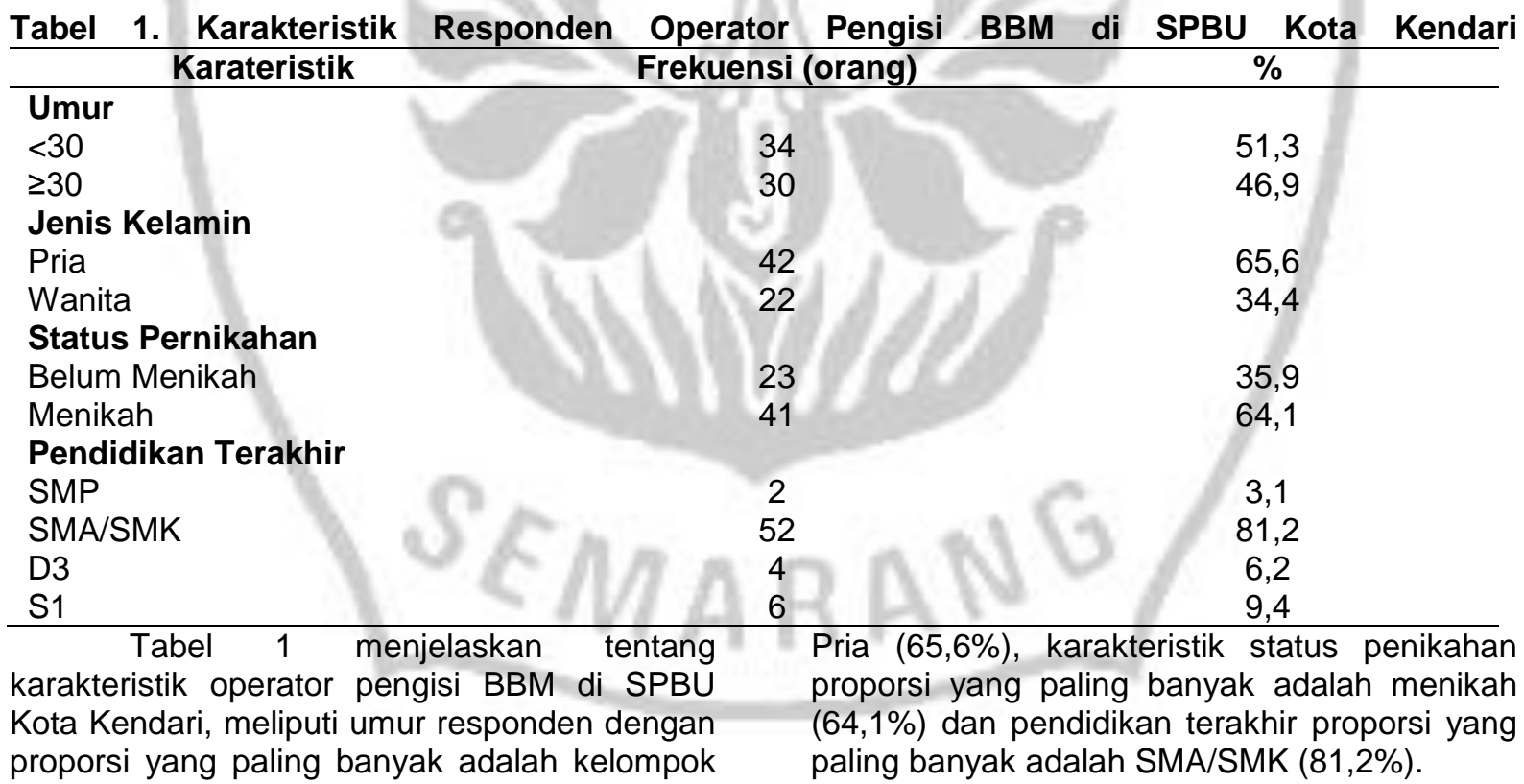


Tabel 2. Hasil Analisis Faktor-Faktor yang berhubungan dengan Keluhan Carpal Tunnel Syndrome pada Petugas Operator Pengisi BBM di SPBU Kota Kendari

\begin{tabular}{|c|c|c|c|c|c|c|c|}
\hline \multirow{3}{*}{ Variabel Independen } & \multicolumn{4}{|c|}{ CTS } & \multirow{2}{*}{\multicolumn{2}{|c|}{ Total }} & \multirow{3}{*}{$P$-value } \\
\hline & \multicolumn{2}{|c|}{$\begin{array}{l}\text { Ada } \\
\text { Keluhan }\end{array}$} & \multicolumn{2}{|c|}{$\begin{array}{l}\text { Tidak Ada } \\
\text { Keluahan }\end{array}$} & & & \\
\hline & $\mathbf{n}$ & $\%$ & n & $\%$ & $\mathbf{N}$ & $\%$ & \\
\hline \multicolumn{8}{|l|}{ Postur Kerja } \\
\hline Risiko Sedang & 21 & 70 & 9 & 30 & 30 & 100 & \multirow{2}{*}{0,000} \\
\hline Risiko Kecil & 7 & 20,6 & 27 & 79.4 & 34 & 100 & \\
\hline \multicolumn{8}{|l|}{ Masa Kerja } \\
\hline Lama & 24 & 55,8 & 19 & 44,2 & 43 & 100 & \multirow{3}{*}{0,012} \\
\hline Baru & 4 & 19 & 17 & 81 & 21 & 100 & \\
\hline \multicolumn{7}{|l|}{ Gerakan Berulang } & \\
\hline Sering & 11 & 73,3 & 4 & 26,7 & 15 & 100 & \multirow{3}{*}{0,019} \\
\hline Jarang & 17 & 34,7 & 32 & 65,3 & 49 & 100 & \\
\hline \multicolumn{7}{|l|}{ Riwayat Penyakit } & \\
\hline Ada Riwayat Penyakit & 7 & 63,6 & 4 & 36,4 & 11 & 100 & \multirow{2}{*}{0,188} \\
\hline Tidak Ada Riwayat Penyakit & 21 & 39,6 & 32 & 60,4 & 53 & 100 & \\
\hline \multicolumn{8}{|l|}{ Status Gizi } \\
\hline Berisiko & 9 & 52,9 & 8 & 47,1 & 17 & 100 & \multirow{2}{*}{0,544} \\
\hline Tidak Berisiko & 19 & 40,4 & 28 & 59,6 & 47 & 100 & \\
\hline
\end{tabular}

Berdasarkan tabel 2 diketahui bahwa terdapat hubungan antara postur kerja $(\rho$-value $=$ $0,000)$, masa kerja ( $\rho$-value $=0,012)$, gerakan berulang $(\rho$-value $=0,019)$, namun tidak terdapat hubungan antara riwayat penyakit ( $\rho$-value $=$ $0,188)$, status gizi $(\rho$-value $=0,544)$.

\section{PEMBAHASAN}

Hubungan Postur Kerja dengan Keluhan Carpal Tunnel Syndrome

Berdasarkan Tabel 2 dimana hasil penelitian didapatkan $\rho$-value $=0,000$ sehingga terdapat hubungan yang signifikan antara postur kerja dengan keluhan Carpal Tunnel Syndrome pada pekerja pengisi BBM di SPBU Kota Kendari. Pekerjaan operator pengisi BBM di SPBU adalah pekerjaan yangkonstan dan banyak melakukan gerakan repetitif, dimana jika dilakukan dalam jangkawaktu yang lama dapat menimbulkan terjadinya penebalan sarung tendon dan timbul penekanan pada tendon pergelangan tangan. ${ }^{5} \mathrm{Jika}$ posisi telapak tangan dengan lengan bawah tidak sesuai dengan faal kerja dan bertahan dalam waktu yang lama, maka gerakan yang ditimbulkan pada manus akan menyebabkan gesekan yang berlebihan dari tepi ligamentum carpi transversumdengan saraf medianus. Sehingga terjadi penebalan pada ligamentum carpi transversum, penebalan ini menyebabkan carpal tunnel menjadi sempit dan menekan saraf sehingga menimbulkan Carpal Tunnel Sundrome. ${ }^{6}$

Sebagian besar responden pada penelitian ini memiliki keluhan Carpal Tunnel
Syndromedan mempunyai postur kerja dengan tingkat resiko sedang. Postur kerja risiko sedang yang dimiliki operator pengisi BBM di SPBU harus dilakukanperbaikan dalam waktu dekat. Pekerjaan yang monoton dan gerakan berulang yang dilakukan oleh operator pengisi BBM di SPBU dapat menyebabkan timbulanya keluhan Carpal Tunnel Syndrome. Pada umumnya pada saat bekerja operator memakai kedua tangannya, dimana tangan kanan dipakai untuk memegang nozzle dan memencet tombol keypad dan tangan kiri dipakai untuk memegang uang, ini tergantung dari kebiasaan operator dan posisi pada saat memberikan pelayanan. Gerakan seperti membengkokkan dan meluruskan lengan bawah, membengkokkan dan meluruskan pergelangan tangan, posisi badan memutar, posisi gerakan pada bahu, posisi pada saat tangan memutar, dan beratnya suatu beban yang di angkat dapat mempengaruhi nilai dalam penentuan level risiko, dimana semakin tinggi level risiko semakin besar peluang untuk terjadi Carpal Tunnel Syndrome. Tidak hanya itu umur dan masa kerja operator merupakan salah satu penyebab timbulnya keluhan Carpal Tunnel Syndrome.

\section{Hubungan Masa Kerja dengan Keluhan Carpal Tunnel Syndrome}

Berdasarkan Tabel 2 dimana hasil penelitian didapatkan $\rho$-value $=0,012$ yang artinya terdapat hubungan yang signifikan antara masa kerja dengan keluhan Carpal 


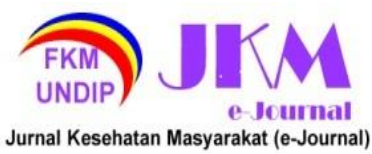

Tunnel Syndrome terhadap operator pengisi BBM di SPBU Kota Kendari.

Petugas operator pengisi BBM di SPBU

Kota Kendari sebagian besar bekerja $\geq 4$ tahun. Peningkatan masa kerja secara otomatis pergerakan tangan dan jari-jari dalam menekan nozzleakan menyebabkan peningkatan gerakan repetitif dengan waktu yang cukup lama. Semakin lama operator bekerja akan terjadi peningkatan risiko untuk munculnya gejala Carpal Tunnel Syndrome

Masa kerja dapat mengimplikasikan lamanya suatu paparan di sebuah tempat kerja, risiko penyakit akibat kerja akan meningkat sesuai dengan peningkatan masa kerja. ${ }^{8}$ Masa kerja adalah salah satu aspek yang bisa menimbulkan muculoskeletal akibat pekerjaan. Petugas yang memiliki masa kerja lama akan sering melakukan gerakan repetitif pada jari tangan dalam waktu yang lama. Jika masa kerja $\geq 4$ tahun maka Carpal Tunnel mudah untukmengalami stres pada jaringan sehingga menyebabkan Carpal Tunnel Syndrome. ${ }^{9}$

Proporsi Carpal Tunnel Syndrome banyak ditemui pada pekerja yang memiliki masa kerja $\geq 4$ tahun, dari pada responden yang memiliki masa kerja $\leq 4$ tahun yang mengalami kejadian positif. Banyaknya masa kerja seseorang akan mempengaruhi penambahan gerakan repetitif yang dilakukan oleh pekerja. ${ }^{10}$

Berdasarkan penelitian yang dilakukan oleh Hartanti (2018) dapat disimpulkan bahwa masa kerja yang panjang mempunyai odds ratio paling besar daripada variabel yang lain seperti posisi janggal, lama kerja, IMT, dan umur. Masa kerja yang panjang mempunyai risiko 9 kali lebih besar untuk merasakan keluhan Carpal Tunnel Syndrome. ${ }^{11}$

\section{Hubungan Gerakan Berulang dengan Keluhan Carpal Tunnel Syndrome}

Berdasarkan Tabel 2 dimana hasil penelitian didapatkan $\rho$-value $=0,019$ yang artinya terdapat hubungan yang signifikan antara gerakan berulang dengan keluhan Carpal Tunnel Syndrome terhadap operator pengisi BBM di SPBU Kota Kendari.

Petugas operator pengisi BBM di SPBU yang melakukan gerakan berulang dengan kategori sering atau menekan nozzle $\geq 10$ kali lebih banyak dibandingkan dengan gerakan berulang dengan kategori jarang atau menekan nozzle $<10$ kali.

Gerakan lengan dan tangan yang berulang $\geq 10$ kali permenit akan menimbulkan keluhan Carpal Tunnel Syndrome. Menurut Salvatore R. Dinardi (1997)gerakan berulang sendiri bisa menjadi faktor risiko yang signifikan terhadap Carpal Tunnel Syndrome. ${ }^{14}$ Penekanan nozzle $\geq 10$ kali disebebkan karena kebiasaan individu atau responden, mendapatkan bagian pengisian BBM pada motor, sistem otomatis dari nozzle sudah rusak, dan pada jam-jam tertentu saat konsumen lagi banyak, keadaan ini menyebabkan intensitas penekanan nozzle meningkat dan apabila terjadi terus menerus akan mengakibatkan munculnyaindikasiCarpal Tunnel Syndrome.

Peningkatan tekanan Carpal Tunnel dapat diakibatkan karena gerakan berulang yang dilakukan. Apabila gerakan berulang terjadi secara terus menerus dan dalam kurun waktu yang lama akan mengakibatkan stres pada jaringan Carpal Tunnel sehingga terjadi permeabilitas pembuluh darah pada pergelangan tangan. Kejadian iskemik saraf yang timbul disebabkan karena gangguan aliran darah sehingga terjadi kerusakan pada saraf dan mengakibatkan gejala menjadi muncul. Gangguan sensorik dan motorik akan terjadi namun sesuai dengan sebaran nervus medianus. 15

Trauma akumuatif dari Carpal Tunnel Syndrome terjadi ketika tangan bergerak secara berulang dalam kurun waktu yang lama dan pergerakan jari-jari dan tangan yang banyak. Ketika ini terjadi otot dan ligamen akan meradang disebabkan karena penekanan yang berlebihan sehingga menghambat Carpal Tunnel. ${ }^{9}$

Penelitian ini didukung oleh penelitian yang dilakukan oleh Sekarsari dkk (2017) pada pekerja pemecah batu di Kecamatan Moramo Utara Kabupaten Konawe Selatan tahun 2016. ${ }^{3}$ menyatakan ada hubungan yang signifikan antara gerakan repetitif dengan Carpal Tunnel Syndrome. Hal ini terjadi karena gerakan berulang yang dilakukan pemecah batu termasuk dalam frekuensi tinggi. Pada saat bekerja pemecah batu melakukan gerakan berulang lebih dari 30 kali per menit. Peningkatan gerakan berulang akan terjadi jika pekerja mengiingkan ukuran pecahan batu yang labih kecil. Penelitian yang dilakukan oleh Al Kirom dan Ardi (2019) juga menunjukkan adanya hubungan yang signifikan ketika operator pengisi BBM menekan nozzle dengan kejadian Carpal Tunnel Syndrome di 3 SPBU Kota Yogyakarta. Penelitian Riccò dan Signorelli (2017)juga tercatat bahwa gerakan berulang secara signifikan menyebabkan peningkatan risiko Carpal Tunnel Syndrome dimana gerakan berulang berisiko 3 kali untuk mengalami Carpat Tunnel Syndrome dari pada yang tidak melakukan gerakan berulang. 


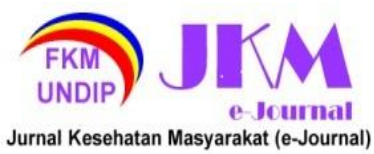

\section{Hubungan Riwayat Penyakit dengan Keluhan Carpal Tunnel Syndrome}

Berdasarkan Tabel 2 dimana hasil penelitian didapatkan $\rho$-value $=0,188$ yang artinya tidak terdapat hubungan yang signifikan antara riwayat penyakit dengan keluhan Carpal Tunnel Syndrome terhadap operator pengisi BBM di SPBU Kota Kendari.

Pada penelitian ini operator pengisi BBM lebih banyak yang tidak memiliki riwayat penyakit $(60,4 \%)$ pada saat bekerja di SPBU, sebagian besar yang memiliki riwayat penyakit tidak merasakan gejala pada saat dilakukannya phalen test maupun dalam pengisian BCTQ, dan penentuan bahwa responden memiliki riwayat penyakit penyebab Carpal Tunnel Syndrome hanya berdasarkan pengetahuan responden, peneliti tidak melakukan penelusuran rekam medis responden secara mendalam. Berdasarkan data yang didapatkan pada saat penelitian, responden yang memiliki riwayat penyakit sebagian besar melakukan gerakan berulang dengan kategori jarang yaitu intensitas menekan nozzle dalam 1 menit $<10$ sehingga mengurangi gerakan serta kekuatan yang memungkinkan menjadi salah satu penyebab tidak munculnya keluhan Carpal Tunnel Syndrome. Beberapa responden juga memiliki riwayat penyakit Arthritis rheumatoid yang dapat menjadi penyebab memunculkan gejala Carpal Tunnel Syndrome namun gejala ini tidak akan nampak ketika pembengkakan tenosynovium belum menekan saraf medianus.

Selaras dengan penelitianNandini (2020)menyatakan tidak terdapat hubungan riwayat penyakit dengan Carpal Tunnel Syndrome. Penelitian yang dilakukan oleh Lazuardi (2016)juga menyatakan bahwa riwayat penyakit tidak berhubungan dengan Carpal Tunnel Syndrome.

\section{Hubungan Status Gizi dengan Keluhan Carpal Tunnel Syndrome}

Berdasarkan Tabel 2 dimana hasil penelitian didapatkan $\rho$-value $=0,544$ yang artinya tidak terdapat hubungan yang signifikan antara riwayat penyakit dengan keluhan Carpal Tunnel Syndrome terhadap operator pengisi BBM di SPBU Kota Kendari.

Petugas operator pengisi BBM pada penelitian ini lebih banyak memiliki status gizi yang tidak berisiko $(73,4 \%)$ dibandingkan dengan yang berisiko (26,6\%). Mereka yang tidak berisiko rata-rata memiliki umur <30 dimana menurut Al Kirom dan Ardi (2019) usia adalah salah satu aspekyang dapat menyebabkan terjadinya Carpal Tunnel
Syndrome,usia $30-60$ tahun dapat meningkatkan risiko terjadinya Carpal Tunnel Syndrome. Berdasarkan observasi pada saat penelitian operator pengisi BBM bekerja dalam posisi berdiri mengangkat nozzle dengan berat kurang lebih $1-1,5 \mathrm{~kg}$ dan melakukan gerakan berulang selama jam kerja, sehingga memungkinkan terjadinya pembakaran kalori oleh gerakan-gerakan yang dilakukan sehingga mencegah penumpukan lemak pada tubuh pekerja.

Pekerja yang memiliki tubuh ramping atau IMT $<25$ lebih tidak berisiko mengalami Carpal Tunnel Syndrome daripada pekerja dengan IMT $\geq 25$ atau berat badan yang berlebihan. Menurut American Obesity Association terdapat $70 \%$ penderita Carpal Tunnel Syndrome yang mempunyai berat badan berlebih dan jika terjadi penambahan IMT 8\% akan menyebabkan kemungkinan terjadinya Carpal Tunnel Syndrome. ${ }^{20}$

Selaras dengan penelitian Wulandari (2016) menyatakan tidak terdapat hubungan bermakna status gizi dengan keluhan Carpal Tunnel Syndrome pekerja pemetik cabai. Namun berbeda dengan penelitian Nadhifah dkk (2018) menyebutkan seseorang yang berstatus gizi tidak normal berisiko 5 kali mengalami Carpal Tunnel Syndrome daripada yang berstatus gizi normal. Hal ini disebabkan adanya penumpukan cairan pada terowongan pergelangan tangan hingga bertambahnya risiko Carpal Tunnel Syndrome.

\section{KESIMPULAN}

Faktor aktivitas reponden seperti postur kerja, masa kerja, gerakan berulang berhubungan dengan Carpal Tunnel Syndrome.

\section{DAFTAR PUSTAKA}

1. Lazuardi Al, Ma'rufi I, Hartanti RI. Determinan Gejala Carpal Tunnel Syndrome (CTS) pada Pekerja Pemecah Batu (Studi pada Pekerja Pemecah Batu di Kecamatan Sumbersari dan Sukowono Kabupaten Jember). Artik IIm Has Penelit Mhs. 2016;

2. Al Kirom DS, Ardi SZ. Hubungan Antara Usia, Durasi Kerja Dan Gerakan Repetitif Menekan Nozzle Dengan Keluhan Subyektif Carpal Tunnel Syndrome (CTS) Pada Petugas Operator Pengisi BBM Di Tiga SPBU Kota Yogyakarta Tahun 2019. 2019;

3. Sekarsari D, Pratiwi A, Farzan A. Hubungan Lama Kerja, Gerakan Repetitif Dan Postur Janggal Pada 


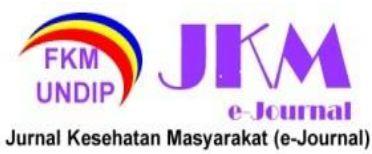

JURNAL KESEHATAN MASYARAKAT (e-Journal)

Volume 9, Nomor 5, September 2021

ISSN: 2715-5617 / e-ISSN: 2356-3346

http://ejournal3.undip.ac.id/index.php/jkm
Tangan Dengan Keluhan Carpal Tunnel Syndrome (Cts) Pada Pekerja Pemecah Batu Di Kecamatan Moramo Utara Kabupaten Konawe Selatan Tahun 2016. Jimkesmas. 2017;2(6):186728.

4. Utamy RT, Kurniawan B, Wahyuni I. Literature Review: Faktor Risiko Kejadian Carpal Tunnel Syndrome (CTS) Pada Pekerja. 2020;8(9):601-8.

5. Tarwaka. Ergonomi untuk Keselamatan, Kesehatan Kerja dan Produktivitas. Surakarta: UNIBA; 2004.

6. Agustin CPM, Mardiana, Budiono I. Hubungan Masa Kerja dan Sikap Kerja dengan Kejadian Sindrom Karpal pada Pembatik CV. Pustaka Beruang Lasem. 2014;3(4):74-80.

7. Putra RL, Alief HF, Grand PB. Hubungan Masa Kerja Dengan Kejadian CTS Pada Pekerja Pemetik. 2016;12:24-9.

8. Juniari GAR, Triwahyudi A. Hubungan antara Masa Kerja terhadap Keluhan Carpal Tunnel Syndrome (CTS) pada Pegawai Perempuan di Kampus Universitas Dhyana Pura yang Bekerja Menggunakan Komputer. VIRGIN J IIm Kesehat Dan Sains [Internet]. 2015;1(2):162-8. Available from: https://jurnal.undhirabali.ac.id/index.php /virgin/article/view/64

9. Muthoharoh, Basri K S, Nuraeni T. Faktor yang Berhubungan dengan Kejadian Carpal Tunnel Syndrome (CTS) pada Karyawan SPBE Di Indramayu. Afiasi $\mathrm{J}$ Kesehat Masy. 2018;3(2):37-44.

10. Hartanti dkk. Faktor Risiko yang Berhubungan dengan Keluhan Carpal Tunnel Syndrome pada Pekerja Operator Komputer Bagian Redaksi di Harian Metropolitan Bogor Tahun 2018. J Mhs Kesehat Masyaraka. 2018;

11. Rina T. Hubungan Repetitive Motion dengan Keluhan Carpal Tunnel Syndrome pada Pekerjaan menjahit di Bagian Konveksi I PT. Dan liris Sukoharjo. 2010;61. Available from: https://digilib.uns.ac.id/dokumen/downl oad/22789/NDc5NTQ=/Hubungan-

Repetitive-Motion-dengan-Keluhan-

Carpal-Tunnel-Syndrome-pada-

Pekerjaan-Menjahit-di-Bagian-

Konveksi-I-Pt-Dan-Liris-Sukoharjoabstrak.pdf

12. Harkitasari S, M, Cahyawati dr. PNMS, Suci. Hubungan Masa Kerja dengan
Carpal Tunnel Syndrome pada Karyawan Pengguna Komputer di PT. Bank Danamon Indonesia, Tbk Denpasar, Bali. Bagian Neurol Fak Kedokt dan IImu Kesehat Univ Warmadewa. 2019;

13. Riccò M, Signorelli C. Personal And Occupational Risk Factors For Carpal Tunnel Syndrome. 2017;68(2):199_ 209.

14. Noprianti DS, Fauzan A, Kes M, Ernadi E, Kes M. Berulang Dengan Kejadian Carpal Tunnel Syndrome Pada Penjahit Busana Mawar Banjarmasin Tahun 2020. 2020;

15. Nandini RF. Program studi kesehatan masyarakat fakultas kesehatan masyarakat universitas sriwijaya 2020. Universitas Sriwijaya; 2020.

16. Lazuardi Al. Determinan Gejala Carpal Tunnel Syndrome (CTS) pada pekerja pemecah batu (Studi pada Pemecah batu di Kecamatan Sumbersari dan Sukowono Kabupaten Jember). Universitas Jember; 2016.

17. Mukhlisa AN. Gambaran Risiko Kejadian Carpal Tunnel Syndrome (CTS) pada Pekerja Wanita di PT. Bogatama Marinusa Makassar [Internet]. Universitas Islam Negeri Alauddin Makassar; 2014. Available from:

http://dx.doi.org/10.1016/j.respol.2011.0 9.003\%0Ahttps://doi.org/10.1016/j.worl ddev.2020.104995\%0Ahttp://dx.doi.org/ 10.1016/j.worlddev.2009.12.011\%0Ahtt p://publicaciones.eafit.edu.co/index.php lecos-

economia/article/view/1969/1978\%0Aht tps://doi.org/10.1016

18. Wulandari NN. Hubungan Umur, Masa Kerja, IMT dan Frekuensi Gerakan Repetitif dengan Kejadian Carpal Tunnel Syndrome. J Kesehat Masy Univ Muhammadiyah Semarang. 2016;A513.1-A513.

19. Nadhifah J, Hartanti RI, Indrayani R. Keluhan Carpal Tunnel Syndrome pada Pekerja Sortasi Daun Tembakau ( Studi di Gudang Restu I Koperasi Agrobisnis Tarutama Nusantara Jember). 2018;6(1):18-26. 